\title{
Sedation for upper gastrointestinal endoscopy: results of a nationwide survey
}

\author{
T K Daneshmend, G D Bell, R F A Logan
}

\begin{abstract}
A postal questionnaire inquiring about routine sedation and premedication practice for upper gastrointestinal endoscopy was sent to 1048 doctors. Of 665 appropriate returns, $81 \%$ were from consultant physicians and surgeons. Most endoscopists (90\%) reported using an intravenous benzodiazepine for at least three quarters of endoscopies and $54 \%$ of physicians and $69 \%$ of surgeons always did so. Midazolam was the intravenous sedative used by a third of all respondents and $13 \%$ also used an additional intravenous agent, usually pethidine. Over the previous two years a total of 119 respiratory arrests, 37 cardiac arrests, and $\mathbf{5 2}$ deaths were identified. Adverse outcomes were reported more frequently by consultant physicians, by those who 'titrated' the intravenous sedative, and by those who used an additional intravenous agent, but were reported equally frequently by endoscopists using midazolam and endoscopists using diazepam. There is an urgent need for a prospective study to identify the circumstances and risk factors associated with adverse outcomes related to endoscopy.
\end{abstract}

Gastrointestinal endoscopy is now widely available in Britain and is generally safe. On the basis of figures from the Trent region we estimate that about 400000 are performed yearly in Britain. ${ }^{1}$ Endoscopy is increasingly carried out on the 'old' old and the very sick. Most endoscopies are performed using intravenous sedation with a benzodiazepine which can occasionally produce severe hypoventilation and hypoxia. ${ }^{2-6}$ Adverse outcomes of endoscopy are uncommon but fatalities occur, as noted in several recent reports. ${ }^{7-10}$ In the United States 66 deaths after sedation with intravenous midazolam have been reported to the Federal Drug Administration and the Committee on Safety of Medicines has received similar reports. ${ }^{11}$

The pattern of premedication and sedation currently in use in Britain is largely unknown. There is also little information about the frequency of adverse outcomes associated with endoscopy. The aim of this study was to establish the pattern of current practice and to make a preliminary estimate of the frequency of adverse outcomes and their possible association with the use of particular drugs.

\section{Methods}

We sent an anonymous questionnaire to 1048 doctors who were identified as endoscopists from the mailing list of one of the major suppliers of endoscopy equipment in the United Kingdom
(KeyMed Ltd). The questionnaire and covering letter were mailed by KeyMed in September 1988, and completed questionnaires were returned to the Department of Community Medicine and Epidemiology. If no reply had been received by November 1988 a second questionnaire was sent by KeyMed.

The questionnaire was contained on two sides of an A4 sheet and consisted of 10 questions (Table I). Although the questionnaires were designed to be self coding, all completed questionnaires were inspected for inconsistencies and coding errors before being included on the data file. Missing or unclear responses to questions were coded as missing. The data were checked by double entry key punching and by checking extreme values against the relevant returned questionnaires.

\section{Results}

By December 1988, 676 questionnaires had been returned. In 11 the respondents stated that they had either stopped performing endoscopy or performed all endoscopies under general anaesthesia. Thus 665 questionnaires were suitable for analysis. A further 20 questionnaires were returned too late to be included in the analysis.

\section{GRADE AND SPECIALTY AND NUMBER OF} ENDOSCOPIES PERFORMED

As Table II shows, $81 \%$ of respondents were consultants in surgery or general medicine, including gastroenterology. The number of respondents in junior hospital posts in medicine and surgery respectively was so small that they have been combined according to status or specialty. Consultant physicians reported doing more endoscopies than consultant surgeons, and this was mirrored by the junior doctors in medicine, of whom $69 \%$ reported performing more than 30 endoscopies in the previous month compared with $25 \%$ of junior surgeons.

\section{PREMEDICATION AND SEDATION}

Table I shows the overall pattern of routine practice reported; $63 \%$ of respondents used a local anaesthetic for the oropharynx for most endoscopies and $23 \%$ also used an anticholinergic agent routinely. There were small differences in practices reported by the various groups. Consultant and junior surgeons tended to use hyoscine butylbromide (Buscopan) (14\%) rather than atropine $(7 \%)$, whereas consultant and junior physicians showed no preference. More consultant and junior surgeons (69\%) reported always using intravenous sedation than other groups $(54 \%)\left(\chi^{2}=13.2, \mathrm{p}<0.001\right)$ but 


\section{TABLE I Survey of sedation and premedication practice for upper gastrointestinal endoscopy}

The purpose of this short questionnaire is to determine what are the patterns of standard practice in the UK and assess the frequency of any adverse outcomes. If you have other staff doing endoscopy under your supervision and who have not received a questionnaire, please give them the spare copy or a photocopy to complete. All questionnaires are anonymous. Please would you fill in the boxes with the appropriate response
Please fill in box with appropriat

1. Your present grade/status is:

$\begin{array}{llrlll}1 & \text { Cons Phys/Gastroenterologist } & 42 \% & 5 & \text { Reg/SHO in Medicine } & 2 \% \\ 2 & \text { Cons Surgeon } & 39 \% & 6 & \text { Reg/SHO on Surgery } & 3 \% \\ 3 & \text { SR/Lecturer in Medicine/GE } & 4 \% & 7 & \text { Clin Assistant/GP } & 3 \% \\ 4 & \text { SR/Lecturer in Surgery } & 3 \% & 8 & \text { Other (state) ................. } & 3 \%\end{array}$

How many upper GI endoscopies (including oesophageal

dilatations but not intubation or ERCP) did you or other staff dilatations but not intubation or ERCP) did you
under your supervision do in the last month?

1 Less than $5 \quad 8 \% \quad 4 \quad 31-45$

$\begin{array}{llrrr}1 & \text { Less than } 5 & 8 \% & 4 & 31-45 \\ 2 & 6-15 & 23 \% & 5 & 46-60\end{array}$

3 16-30

$26 \%$

6 61-75 $\begin{array}{lll}7 & 76-100 & 5 \% \\ 8 & \text { more than } 100 & 4 \%\end{array}$

Yourself

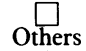

$4 \%$

Subsequent questions relate to your own practice

3. Do you give a local anaesthetic for mouth and pharynx?
1 Yes, always
$49 \% \quad 3$ Yes, occasionally
$16 \%$
2 Yes, usually
$14 \% \quad 4$ Never
$20 \%$

4. Do you use an anticholinergic agent routinely?
1 Yes, atropine
Yes, Buscopan (hyoscine
9\% $\quad 3$ Yes, other
Yes, other
No
$77 \%$
butylbromide)
$13 \%$

5. Sedation

(a) Do you use intravenous sedation for your upper endoscopies?

Yes, always

2 Yes, more than $3 / 4$

$\begin{array}{lll}62 \% & 4 & \text { Yes, } \\ 28 \% & 5 & \text { None } \\ 2 \% & & \end{array}$

(b) If YES, is it

1 Diazepam

2 Diazemuls

c) Do you roucin

$\begin{array}{rrl}5 \% & 4 & \text { Droperidol } \\ 59 \% & 5 & \text { Other (please }\end{array}$

Other (please

$0 \%$

(c) Do you routinely use other intravenous drugs in

conjunction with those mentioned in 5(b)?

1 Yes

$13 \% \quad 2$ No

ate)

$1 \%$

(d) If YES, is it

1 Pethidine

$55 \%$

(e) How are intravenous drugs given?

1 As a bolus

$36 \%$

2 Other (state) ...........

(f) For how long

2 Titrated

$63 \%$

1 Less than 1 year

routine practice?

2 More than one year $\quad 98 \%$

6. How often have your patients needed oxygen during or after endoscopy?
1 Never
$41 \%$
3 3-8 times a year
4 About monthly or more often
$9 \%$
Once or twice a year

$48 \%$

In the past 2 years, as far as you (or your nursing staff) can recall, after endoscopy? (Put numbers in boxes or 0 if nil)

1 Severe hypoventilation requiring oxygen

2 Respiratory arrest requiring resuscitation but short of cardiac arrest

3 Cardiac arrest

4 Death (only those where endoscopy may have contributed)

8. In the past 2 years, how many times have you or the nursing staff called the cardiac arrest team for one of the above?

9. In the past years do you know of any patients being endoscoped by others in your hospital who have suffered a respiratory or cardiac arrest or death?
1 Yes, 1 or 2
$34 \%$
$6 \%$
$\begin{array}{ll}3 & \text { Yes, } 5 \text { or more } \\ 4 & \text { No }\end{array}$
2 Yes, 3-4
$60 \%$

10. Any comments about your own practice or experience of adverse outcomes?

agents $\left(\chi^{2}=1 \cdot 3, \mathrm{p}>0 \cdot 1\right)$. A slightly greater proportion of consultant and junior surgeons gave intravenous drugs as a bolus compared with consultant and junior physicians $(41 \% v 34 \%$; $\left.\chi^{2}=2 \cdot 1, \mathrm{p}>0 \cdot 1\right)$.

\section{ADVERSE OUTCOMES REPORTED}

The overall frequency of adverse outcomes reported is given in Table III. A total of 52 deaths was reported by 48 respondents, of whom four reported two deaths each. A further 119 respiratory arrests and 37 cardiac arrests were also reported. Most endoscopists (59\%) said that they had patients who needed supplementary oxygen at least once a year: $40 \%$ could recall having patients in the previous two years with severe hypoventilation and $11 \%$ of endoscopists recalled that this occurred on three or more occasions.

The frequency of adverse outcomes was analysed in terms of the grade and specialty of the respondents, number of endoscopies performed, type of intravenous sedation used, use of additional sedation, and whether sedation was given as a bolus or titrated according to effect. Consultant physicians reported more adverse outcomes than other groups (Table III). This was accounted for in part by the greater number of endoscopies they reported performing. Although there was a tendency for adverse outcomes to be more commonly reported as the number of endoscopies increased, this trend was mainly due to the much lower frequency of adverse outcomes reported by endoscopists doing fewer than 15 endoscopies in the previous month (Table IV).

The type of intravenous benzodiazepine used seemed to be unrelated to the frequency of adverse outcomes being reported equally often by users of diazepam and midazolam (Table V).

Those who 'titrated' sedation more frequently reported adverse outcomes than those who gave intravenous sedation as a bolus injection. Episodes of severe hypoventilation were reported by $47 \%$ of those who titrated sedation compared to $37 \%$ of those who gave a bolus injection $\left(\chi^{2}=5 \cdot 1, p<0 \cdot 05\right)$.

Adverse outcomes were reported more frequently by respondents who used other intravenous sedation, usually pethidine, in addition to a benzodiazepine (Table V). Of the 82 respondents who used other intravenous sedation, $43(52 \%)$ reported having patients with severe hypoventilation compared with $223(40 \%)$ of the 557 respondents not using other intravenous sedation $\left(\chi^{2}=4.5, p<0.05\right)$.

Comments about their own practice or experience of adverse outcomes were added by 301 respondents. These mainly consisted of accounts of adverse outcomes usually in patients with cardiorespiratory disease or comments on the rarity of problems. Ten respondents commented on problems associated with joint use of pethidine and a benzodiazepine. Thirty nine respondents commented on their experience with midazolam compared with diazepam. Of these, 17 commented favourably about its safety and amnesic effect. Thirteen respondents, 10 of whom used midazolam routinely, cautioned the proportion who used sedation for half of endoscopies was similar in all groups. Midazolam was used by about a third of respondents in all groups except for clinical assistant and general practitioner endoscopists, of whom 10 of 17 used midazolam. Ten per cent of consultant and junior physicians compared to $14 \%$ of surgeons reported using additional intravenous 
TABLE II Reported number of endoscopies performed in previous month according to grade and specialty

\begin{tabular}{|c|c|c|c|c|c|c|}
\hline \multirow[b]{2}{*}{$\begin{array}{l}\text { No of } \\
\text { endoscopies }\end{array}$} & \multicolumn{2}{|c|}{ Consultant (\%) } & \multirow{2}{*}{$\begin{array}{l}\text { Senior registrars or } \\
\text { lecturers }(\%) \\
(n=48)\end{array}$} & \multirow{2}{*}{$\begin{array}{l}\text { Registrars or senior } \\
\text { house officers }(\%) \\
(n=33)\end{array}$} & \multirow[b]{2}{*}{$\begin{array}{l}\text { Others (\%) } \\
(n=37)\end{array}$} & \multirow[b]{2}{*}{$\begin{array}{l}\text { Total }(\%) \\
\left(n=625^{\star}\right)\end{array}$} \\
\hline & $\begin{array}{l}\text { Physicians } \\
(n=26 I)\end{array}$ & $\begin{array}{l}\text { Surgeons } \\
(n=246)\end{array}$ & & & & \\
\hline$<5$ & 5 & 10 & 10 & 6 & 14 & 8 \\
\hline $6-15$ & 15 & 35 & 10 & 30 & 14 & 23 \\
\hline $16-30$ & 23 & 29 & 25 & 24 & 27 & 26 \\
\hline $31-45$ & 23 & 13 & 23 & 18 & 32 & 19 \\
\hline $46-60$ & 16 & 4 & 21 & 6 & 11 & 11 \\
\hline $61-100$ & 13 & 6 & 10 & 9 & 3 & 9 \\
\hline$>100$ & 7 & 3 & 0 & 6 & 0 & 4 \\
\hline
\end{tabular}

${ }^{\star}$ For 40 information about status or number of endoscopies was missing.

TABLE III Adverse outcomes reported by grade and specialty of respondents

\begin{tabular}{|c|c|c|c|c|c|}
\hline & $\begin{array}{l}\text { Consultant } \\
\text { physicians } \\
(n=268)(\%)\end{array}$ & $\begin{array}{l}\text { Consultant } \\
\text { surgeons } \\
(n=249)(\%)\end{array}$ & $\begin{array}{l}\text { Junior } \\
\text { physicians } \\
(n=42)(\%)\end{array}$ & $\begin{array}{l}\text { Junior } \\
\text { surgeons } \\
(n=40)(\%)\end{array}$ & $\begin{array}{l}\text { Others } \\
(n=38) \\
(\%)\end{array}$ \\
\hline $\begin{array}{l}\text { Severe hypoventilation } \\
\text { Respiratory arrst } \\
\text { Cardiac arrest } \\
\text { Death }\end{array}$ & $\begin{array}{r}52 \\
23 \\
9 \\
12\end{array}$ & $\begin{array}{r}30 \\
6 \\
0 \\
3\end{array}$ & $\begin{array}{r}57 \\
12 \\
7 \\
2\end{array}$ & $\begin{array}{r}33 \\
5 \\
3 \\
5\end{array}$ & $\begin{array}{l}37 \\
16 \\
11 \\
11\end{array}$ \\
\hline
\end{tabular}

about difficulties in elderly and frail patients and the need for small doses, and nine respondents who reported using Diazemuls routinely added comments about a tendency to oversedate with midazolam.

\section{Discussion}

This survey was carried out to establish the pattern of routine premedication and sedation practice and to make a preliminary assessment of the frequency of adverse outcomes. The number of doctors approached and their response rate need to be considered in the light of these objectives. As expected, the sample was heavily weighted in favour of consultants. Although we omitted to ask doctors who did not do upper gastrointestinal endoscopy to return their questionnaires, some did return them indicating this and we suspect that many unreturned questionnaires were sent to doctors who did not do endoscopy. Nevertheless, the number of replies was sufficiently large that we think at least half and possibly three quarters of all consultants who do regular endoscopy responded. There is no reason to think that non-response has biased our assessment of what is routine premedication and sedation practice by consultants. It also seems unlikely that the practice of their junior hospital staff would be appreciably different.

The survey has established that in general premedication and sedation practice is fairly uniform. Over $90 \%$ of respondents use an intravenous benzodiazepine, mostly with local oropharyngeal anaesthesia but no other intravenous drugs. A few, however, reported routinely using other intravenous sedatives as well, usually pethidine, and these endoscopists also reported having more patients who required oxygen for hypoventilation. Taken together with the spontaneous comments we received, this supports the view that the use of pethidine for sedation for endoscopy is relatively hazardous. We found no evidence that adverse outcomes were more frequently experienced by respondents who used midazolam, but there were sufficient anecdotal statements to suggest that further study is necessary. Our finding that adverse outcomes were more frequently reported by consultant physicians and by those who 'titrate' sedation dose compared to those who give a bolus dose probably reflects differences in the characteristics of the respondents or a more cautious approach based on past experience rather than a causal relation.

As expected, severe hypoventilation was the most frequently reported adverse outcome. Recognition and recall of such episodes is likely to be more variable than for other outcomes to the extent that some might question whether they should be classified as adverse outcomes at all. Hypoventilation is likely to result in a degree of hypoxia, which in a small proportion of endoscopies is severe.$^{56}$ Although the hypoxia is usually of no clinical relevance, the cardiac arrhythmias often observed during endoscopy occur most frequently during periods of maximum oxygen desaturation. ${ }^{51213}$ We suspect, therefore, that sedation practices that are more frequently associated with episodes of severe hypoventilation are also more likely to be associated with more serious adverse outcomes.

As far as the frequency of adverse outcomes is concerned, the reliability of retrospective statements, usually made without the help of records, are obvious. Nevertheless, we think it unlikely that such assessments will greatly inflate the number of such events, particularly the number of deaths. Our respondents recalled a total of 52 deaths over the past two years. From the estimates given of the number of endoscopies performed a month this represents a mortality of one in every 7500 to 11000 endoscopies. It is possible that some deaths have been counted more than once by endoscopists working in the same unit. On the other hand, the underrepresentation of training grades in our respondents may have reduced the numbers reported. Consequently, this estimate must have fairly wide confidence limits. We suspect that the true figure may be as high as 100 or as low as 25 a year.

We did not seek to record the circumstances and patient details for those who died or had other cardiorespiratory complications during or after endoscopy. It is evident, however, that the

TABLE IV Endoscopists' reporting of adverse outcomes by number of endoscopies performed

\begin{tabular}{|c|c|c|c|c|c|c|c|c|c|}
\hline & \multicolumn{9}{|c|}{ Reported No of endoscopies performed in previous month } \\
\hline & $\begin{array}{l}<5 \\
(n=49) \\
(\%)\end{array}$ & $\begin{array}{l}6-15 \\
(n=145) \\
(\%)\end{array}$ & $\begin{array}{l}16-30 \\
(n=161) \\
(\%)\end{array}$ & $\begin{array}{l}31-45 \\
(n=119) \\
(\%)\end{array}$ & $\begin{array}{l}46-60 \\
(n=69) \\
(\%)\end{array}$ & $\begin{array}{l}61-75 \\
(n=27) \\
(\%)\end{array}$ & $\begin{array}{l}76-100 \\
(n=29) \\
(\%)\end{array}$ & $\begin{array}{l}>100 \\
(n=26) \\
(\%)\end{array}$ & $\begin{array}{l}\text { Total } \\
(n=625) \\
(\%)\end{array}$ \\
\hline Severe hypoventilation & 13 & 25 & 47 & 52 & 51 & 50 & 55 & 44 & 41 \\
\hline Respiratory arrest & 2 & 6 & 20 & 13 & 14 & 26 & 31 & 15 & 14 \\
\hline Cardiac arrest & 2 & 2 & 6 & 7 & 9 & 4 & 10 & 0 & 5 \\
\hline Death & 4 & 5 & 7 & 7 & 10 & 22 & 17 & 4 & 8 \\
\hline
\end{tabular}


TABLE V Percentage of respondents reporting adverse outcomes in previous two years by type and method of intravenous sedation routinely used

\begin{tabular}{|c|c|c|c|c|c|c|}
\hline Adverse outcome & $\begin{array}{l}\text { Diazepam/ } \\
\text { Diazemuls } \\
(n=397) \\
(\%)\end{array}$ & $\begin{array}{l}\text { Midazolam } \\
(n=215) \\
(\%)\end{array}$ & $\begin{array}{l}\text { Bolus } \\
(n=195) \\
(\%)\end{array}$ & $\begin{array}{l}\text { Titrated } \\
(n=343) \\
(\%)\end{array}$ & $\begin{array}{l}\text { No other } \\
\text { intravenous } \\
\text { sedation } \\
(n=557) \\
(\%)\end{array}$ & $\begin{array}{l}\text { Other } \\
\text { intravenous } \\
\text { sedation } \\
(n=82) \\
(\%)\end{array}$ \\
\hline \multicolumn{7}{|l|}{ Severe hypoventilation: } \\
\hline At least 1 episode & 42 & 42 & 37 & 47 & 40 & 52 \\
\hline 2 episodes & 13 & 15 & 11 & 17 & 12 & 18 \\
\hline 3 or more episodes & 11 & 11 & 11 & 12 & 12 & 18 \\
\hline Respiratory arrest & 14 & 14 & 15 & 16 & 14 & 18 \\
\hline Cardiac arrest & $4 \cdot 8$ & $5 \cdot 6$ & $4 \cdot 6$ & $5 \cdot 8$ & $4 \cdot 8$ & $6 \cdot 1$ \\
\hline Death & $7 \cdot 5$ & $7 \cdot 5$ & $6 \cdot 1$ & $8 \cdot 5$ & $7 \cdot 0$ & $8 \cdot 5$ \\
\hline
\end{tabular}

number of deaths and other complications reported are sufficient to merit prospective study to identify individual circumstances and risk factors associated with an adverse outcome.

We thank KeyMed Ltd, Southend on Sea, for their mailing list and for for sending out the questionnaire, and Dr Christopher Williams and other members of the Endoscopy Committee of the British Society of Gastroenterology for their helpful comments in the preparation of the questionnaire.
1 Scott B, Atkinson M. Gastroenterology services: a regional review of changes over a five-year period (1981-86). Gut review of changes

2 Lieberman DA, Wuerker GK, Katon RM. Cardiopulmonary risk of esophagogastroduodenoscopy - role of endoscope diameter and systemic sedation. Gastroenterology 1985; 88: $468-72$.

3 Rostykus PS, McDonald GB, Albert RK. Upper intestina endoscopy induces hypoxemia in patients with obstructive pulmonary disease. Gastroenterology 1980; 78: 488-91.

4 Atluri R, Ravry MJR. Effect of intravenous diazepam on arterial oxygen saturation levels (S.A.O.L.) during esophagogastroduodenoscopy (ogd). [Abstract]. Gastrointest Endosc 1978; 24: 191.

5 Rozen P, Fireman S, Gilat T. Arterial oxygen tension changes in elderly patients undergoing upper gastrointestinal endoscopy. II. Influence of the narcotic premedication and endoscopy. II. Influence of the narcotic premedication and

6 Bell GD, Reeve PA, Moshiri M, et al. Intravenous midazolam: a study of the degree of oxygen desaturation occurring during upper gastrointestinal endoscopy. $\mathrm{Br} \mathcal{J} \mathrm{Cli}$ Pharmacol 1987; 23: 703-8.

7 Report of a confidential enquiry into perioperative deaths. Buck N Devlin HB, Lunn JN, eds. London: Nuffield Provincia Hospital Trust/King's Fund, 1987: 43.

8 Vaira D, D'Anna L, Ainley C, et al. Endoscopic sphincterotomy in 1,000 consecutive patients. Lancet 1989; ii: 431-3.

9 Lim AG. Death after flumazenil. Br Med f 1989; 299: 858-9.

10 Daneshmend TK, Logan RFA. Midazolam antagonism. Lancet 1988; ii: 399.

11 Midazolam - is antagonism justified? Lancet 1988; ii: 140-1.

12 Murray A, Kenny GC. Monitoring during sedation and Murray A, Kenny GC. Monitoring

13 Levy N, Abinader E. Continuous electrocardiographic monitoring with Holter electrocardiorecorder throughout al stages of gastrointestinal endoscopy. Am $\mathrm{F}$ Dig Dis 1977; 22 $1091-6$ 